\title{
Why Scientific Research is Imperative for Entrepreneurship and Sustainable Development in Pakistan
}

\section{Bilal U. Haq*}

\begin{abstract}
Indigenous scientific research is vital for a country's long-term economic growth. The simple transference of technology or acquisition of expertise ultimately has developmental limitations. Examples from the hydrocarbon industry clearly illustrate this paradox: oil-rich developing countries can afford to procure expert advice with ease, but rarely develop the new skills essential to make the next technological breakthrough or scientific paradigm shift. Underlying this failing is often the absence of a culture of open scientific enquiry. For resource-deficient countries, this is compounded by the dearth of infrastructure. Such countries argue that they cannot afford to finance scientific research, although this does not always require large investments up front. Software research and development is a good example, requiring primarily technical knowhow, skilled labor and a desire for innovative success. The deficit of scientific research in Pakistan stems from many of these factors, even though the requisite human resources are available in abundance. Innovation and entrepreneurship requires a special mix of encouragement and incentives from the government and industry. This paper outlines some of these issues based on the author's experience of several decades of research leadership and funding in the US and Europe, and his involvement in transferring advanced scientific knowledge to developing as well as developed countries.
\end{abstract}

Keywords: Scientific research, entrepreneuership, development, Pakistan.

JEL classification: O30, L26.

\section{Introduction}

This short paper contains a rather personal view of science and the economic good it can do nations that heed its promise. I have assembled these views over a period of several decades, both as a practicing research

* Sorbonne University, University Pierre and Marie Curie, Paris VI, and the Smithsonian Institution, Washington, DC.

The author would like to thank the organizers of the symposium at the Lahore School of Economics in April 2016, especially Dr Irfan ul Haque, for inviting him to speak to a group of eminent economists about science and its potential impact on entrepreneurship and sustainable development in Pakistan. 
scientist and as a science facilitator at the US National Science Foundation (NSF), directing a major field of natural sciences, namely, marine and terrestrial geosciences.

This also includes my close involvement with research on global climate change (GCC), which affects all of us. The impact of climate change will be calamitous in countries located in the transition zone between the tropics and temperate latitudes, including Pakistan. Such changes will catch us unprepared if we do not plan in advance and could lead to critical and insoluble socioeconomic problems. My career-long active participation in the transfer of scientific knowledge and technology to both developing and developed countries has given me a vantage point from which to observe how science has been gainfully employed in the service of the public by some countries and what has gone awry in other, not so fortunate, ones.

\section{Abdus Salam's Legacy in Promoting Science in Pakistan}

Professor Abdus Salam, Pakistan's only Nobel laureate in science, was passionate about promoting not only theoretical physics, his own field of inquiry, but also other sciences in developing countries and especially in Pakistan, his much-loved native country. It was this passion for knowledge and the desire to promote it in less well-off countries that led him to propose the creation of an international center for theoretical physics under the aegis of UNESCO. Originally, he envisaged locating the center in Pakistan - a request the country denied, citing insufficient resources as an excuse. The proposed institution was eventually established in Trieste, Italy, which country provided the bulk of funding needed. What a great loss for our country and its science. Pakistan's political leadership has erred on the side of inanity ever since. Science, so important to the country's economic wellbeing, has been largely ignored. As a consequence, Pakistan is now among those countries that spend the lowest per capita on nonmilitary research in the world.

I met Professor Salam during his visit to Stockholm to receive the Nobel Prize in December 1979. I was a postdoctoral docent that year at Stockholm University and had the pleasure of attending the Nobel award ceremonies. I was also charged by my university to host Dr Salam for half a day and facilitate his meeting with resident Pakistani students. Dr Salam took time out to discuss each student's ongoing research individually. He tried to convey to our group his conviction that no country could prosper without indigenous science. He also expressed his frustration over the 
"brain drain" of bright minds to the West, given the lack of research resources in their own countries.

One could easily sense in him not only his passion for science, but also his great ambition to transfer advanced knowledge to countries such as his own. He reminded us that the pursuit of science and higher learning was entirely compatible with the teachings of Islam; it was incumbent upon us to disseminate knowledge to our countrymen and to anyone else who could put it to good use. My brief meeting with him left a great impression on me: I have tried to use him as a role model, especially (albeit in a smaller way) in my own pursuit to transfer scientific knowledge to where it might do the most good. It is time that Pakistan, like the rest of the world, acknowledged the greatness of Professor Salam and his generous role in inspiring a generation of scientists around the globe.

\section{The Importance of Science}

Science and its derivative, technology, lead directly to innovation, which is what powers countries' economic engine. Professor Salam is often cited as saying that, "unless you are very good at science, you will never be good at technology." The hydrocarbon exploration industry clearly shows that the transfer of technology alone - without developing local research and development (R\&D) capabilities - has its limits. For example, oil-rich developing countries, such as those in the Middle East, can afford to buy the best expertise when needed, but usually fail to develop new technologies on their own because they have not fostered a local culture of free scientific enquiry or developed enduring infrastructure. Indeed, without indigenous scientific capabilities, no country can hope to prosper beyond a certain limit, where the use of knowledge is governed largely by expediency.

Scientific research is most often driven by scientists' passion for learning how Nature works. The process of inquiry into Nature generates new ideas that fuel economic growth and enable countries to remain competitive. Hence, the importance of indigenous scientific research and the process of investigation in itself. In the long run, it is not enough to just transfer technical knowledge from those who have it to those who do not. All countries need to develop their own infrastructure for scientific inquiry and discovery. Pakistan - notwithstanding a few bright spots - risks being left so far behind that it will have little hope of catching up with a rapidly advancing world both scientifically and economically. 


\section{The Example of China}

The question that arises is what model Pakistan should follow if it is to realize some semblance of scientific parity with the developed world and the economic growth to which it aspires. The answer is staring us in the face. Not long ago, China was exactly at the same stage of development as Pakistan is now. In fact, at the time of the Cultural Revolution in the 1970s, matters worsened when much of China's existing scientific expertise and infrastructure were destroyed. The country had to rebuild everything from scratch.

Since the end of the Cultural Revolution, it has been my privilege to visit China nearly every year and monitor firsthand the growth of science and technology in the country and how it has fired the growth engine. I was also appointed visiting or honorary professor at several universities that sought my advice, for example, on creating a center of excellence in geosciences at Tongji University in Shanghai. This has given me the opportunity to closely observe the inner workings of their system.

It was impressive to watch China's phenomenal progress in science, along with its economic growth. Every year, Western science agencies have had to revise their estimates and predictions upward. Consequently, China has nearly caught up with the West in most sciences. Its institutions of higher learning house some of the most advanced scientific infrastructure and instrumentation. Chinese science today is an apt example of how academic ideas can be rapidly employed in technology and for practical application in the service of its people. This is the real story of achievement and China's grand entry into the entrepreneurial world.

How has China done it? The first step was a conscious decision on the part of its political leadership to promote science and catch up with the West in the shortest possible time. This purposeful resolution was followed by the equally important decision to invest preferentially in upgrading institutions of higher learning and scientific infrastructure, and to acquire modern instrumentation in all the sciences considered relevant to the country's development. To jumpstart the brainpower it needed, China decided to flood Western universities with government-funded doctoral students. China has been, and continues to be, the country with the most science students in foreign countries. Downstream, it has provided special incentives for its Western-trained scientists so that most of these invaluable professionals return home and are not frustrated by the lack of resources the country has to offer. 


\section{From Science to Innovation}

The realization that there is a direct link between scientific research and entrepreneurship is relatively new. Not long ago, the academic world shunned the "industrial" or "commercial" stain and those professionals who opted to work for commercial enterprises were considered lost to science. This attitude has changed considerably in the last two decades. Today, universities fall over each other to attract industrial funding and to help students and faculty start up their own enterprises. As an example, the NSF, a bastion of fundamental academic research that has funded over 200 Nobel laureates (more than any other agency in the world), is breaking down the barriers between research and commercial development by funding major nodes or hubs of innovation in biotechnology, nanotechnology and computer science. This is a complete turnaround in thinking from just a few years ago and industrial participation in these hubs is an integral component of these plans.

It is often said that "today's pure science is tomorrow's innovation." This quote needs to be modified to "this morning's scientific idea is this afternoon's opportunity" in view of the rapid pace at which new ideas are translated into practical applications and as the speed of both adsorption and absorption of these ideas increases. This rapid conversion of ideas in pure science into innovative applications is the true "entrepreneur-ization" of science.

How do we encourage and sustain this trend? One well-tried method that has met with considerable success downstream has been to foster industrial-academic partnerships with mentors for young researchers from both sectors. This has worked particularly well in the hydrocarbon and chemicals industries, where qualified scientists and technologists can find immediate and innovative employment at the end of their academic training. Perhaps using the NSF's "innovation hub" model would help encourage such partnerships. This model has now been tried in a number of countries with great success, but also requires the government to play a very proactive role.

\section{The "Technopreneur's" Path to Growth and Success}

What about individual entrepreneurship? How can this be fostered? Essentially, it would work the same way as encouraging a broader culture of entrepreneurial innovation. The basis of nearly all individual entrepreneurial success lies in ideas couched in new 
technologies - hence, the term "technopreneur" - that take their cue from scientific advancements. This is exemplified in fields such as cybernetics, biotechnology, nanotechnology and medicine, where new findings are applied rapidly.

In computer science, and especially in software development, innovative talent often lies in the timely recognition that a new or existing technology can be applied afresh. This is where the individual initiative to use the technology as it has never been used before pays high dividends. Nevertheless, the technopreneur's job is not a simple one. Entrepreneurial success requires partnering with someone who has the business acumen needed to market the product once the opportunity has been recognized. Numerous case studies show that most new entrepreneurial ventures fail because they lack a business component.

Figure 1, which illustrates the technopreneur's path to success, shows that both stage 1 (the invention phase) and stage 5 (the development phase) need active scientific input. Securing intellectual property rights early (and guarding against copycats) may not seem very important to a new entrepreneur, but is indeed crucial to the venture's long-term success. Many new enterprises are unable to get off the ground because they fail to obtain enough initial funding (stage 4), which requires convincing third parties to invest in their vision. 
Figure 1: The technopreneur's path to successful innovation



Of course, there are no real substitutes for hard work in an entrepreneur's path to achievement. Entrepreneurial success requires (at least, initially) putting in long hours, employing the right people to help one and focusing on the products or services one will provide. Most wellknown and successful online businesses were dreamt up by individuals who were extremely focused and refused to give up when faced with initial hurdles. An economically healthy country has an abundance of entrepreneurs who will thrive only if the state's policies encourage and foster new businesses with the right trade and tax incentives.

\section{Science and Sustainable Development}

The current German chancellor, Angela Merkel, during her tenure as minister for the environment, wrote an influential editorial in 1998 for Science magazine, ${ }^{1}$ making several important points that are still relevant to sustainable development. She argues that, for a society to adopt a "socioecological" market economy while also aspiring to sustainable

\footnotetext{
${ }^{1}$ See: http://science.sciencemag.org/content/281/5375/336
} 
development, it will have to discriminate better between economic growth and the simple exploitation and consumption of resources. The prevalent pure form of consumerism imperils natural ecosystems and diminishes our ability to preserve natural habitats.

This is where science must step in and provide new and innovative ways to ensure environmental sustainability and economic growth. While society in the developed world is shifting rapidly from a largely industrial base to a knowledge base, heavily polluting industries are being relocated to developing countries where environmental damage is rampant. These countries may end up having to spend large sums on cleaning up their industry (again, China is a good example here). This means that science and innovation will have to play even more important roles in the pursuit of sustainable development.

To achieve sustainability, in future we must constantly remind ourselves of the close link between Nature, society and the economy, and view development through the lens of natural ecological systems. Merkel points out that both policymakers and scientists will have to be cognizant of the links between ecological, economic and social factors when they seek solutions to development issues. She also warns that, in the long term, "progress" can work against us if it continues to be detrimental to Nature. Innovation and individual entrepreneurship will play important roles in development. Thus, sustainable development and entrepreneurship are strongly linked. Developing countries need to be vigilant about environmental degradation: where possible, they should opt for clean, knowledge-based technologies rather than giving in to the ultimately selfdestructive allure of heavily polluting industries.

In her editorial for Science, Merkel lists four areas that she thinks deserve special attention from scientists and innovators: energy use, the closure of substance cycles, environmentally compatible mobility and biotechnology. Under energy use, she includes renewable energies (wind, solar, geothermal) and new propulsion technologies that will help reduce greenhouse gases. She points out that there are opportunities within existing technologies to design new, environmentally friendly production processes - technologies that optimize the use of resources with superefficient, environmentally compatible production methods that reduce waste and promote sustainability.

What an enlightened attitude from this progressive, well-educated policymaker when compared to the conservative stance against science by 
politicians in many countries, including the US. Under the environmentally compatible mobility rubric, Merkel includes better traffic concepts and more energy-efficient automobiles that run preferably on less fuel or on nonpolluting fuels such as natural gas, electricity or hydrogen. In addition, more computer-efficient logistics for goods transportation could cut down transport distances.

Biotechnology innovations are well on their way to revolutionizing many fields, including medicine and therapy. Major advances are to be expected in resolving food shortages and ensuring cleaner industrial and agricultural production, environmental protection and pollution control. Many developing countries could easily build their own advanced capabilities in these areas in a short time and with relatively little investment. Agricultural research in Pakistan already has a strong biotech component and is considered world-class. This could be promoted in other related areas as well at the country's universities.

\section{Pakistan's National Science, Technology and Innovation Policy}

It is very commendable that policymakers in Pakistan have drafted a meaningful national policy on science, technology and innovation. The National Science, Technology and Innovation Policy (NSTIP) 2012 focuses on planning and management structures in these areas and identifies the need for (i) human resource development, (ii) indigenous technology development, (iii) technology transfer and the creation of absorptive capacity, (iv) international cooperation and (v) $R \& D$ in priority areas. Appropriately, it also highlights innovation as a key driver of economic activity.

With the exception of one important omission - cognizance of and planning for GCC - the NSTIP is a sound document that contains everything such a plan ought to have. For example, action items include increasing R\&D expenditure to 1 percent of GDP by 2015 and 2 percent by 2020. The policy aims to restructure management systems to make them more efficient, strengthen monitoring, coordinate provincial reviews of science syllabi, build teachers' skills, equip science labs adequately and standardize training programs. It also aims to establish closer links between academia and industry R\&D, import technical knowledge, develop reverse engineering capabilities and build Pakistan's capacity for technology transfer and absorption. 
Better and wider international cooperation is also deemed essential. Among the priority "thrust areas" the NSTIP lists metrology, environment, health and pharmaceuticals, energy, agriculture and livestock, minerals, ocean resources, electronics, information technology, communications, material science, nanotechnology, lasers, photonics and engineering. All these goals are laudable and make for a comprehensive wish-list. But is it just that, a wish-list? For we have seen little action on this plan since 2012 when it was first published.

Higher literacy rates mean that countries have a greater pool of human resources from which to draw their scientific intelligentsia. Pakistan's expenditure on civilian R\&D (0.67 percent of GDP) is too low for it to hope to catch up with developed countries (Table 1). For a country to build a solid base in sustainable scientific research, one that affects its economy positively and productively, it must spend at least $1.5-2.5$ percent of its GDP on indigenous civilian R\&D. Those that spend less on science are liable to be left behind the mainstream of scientifically well-positioned countries. Pakistan currently spends less than 0.7 percent on nonmilitary $\mathrm{R} \& \mathrm{D}$, which is far too small an amount to address all the action items identified in the NSTIP. Its objective to increase this expenditure to 2 percent by 2020 will require a herculean effort on the part of policymakers.

\section{Table 1: R\&D expenditure and literacy rates for selected countries, 2015}

\begin{tabular}{lccc}
\hline Country & $\begin{array}{c}\text { R\&D, as a \% of } \\
\text { GDP PP }\end{array}$ & $\begin{array}{c}\text { R\&D per capita, } \\
\text { in US\$ }\end{array}$ & Literacy rate, \% \\
\hline Japan & 3.67 & 1,260 & $\approx 99.0$ \\
US & 2.70 & 1,275 & 86.0 \\
Germany & 2.40 & 861 & $\approx 99.0$ \\
China & 2.08 & 248 & 96.4 \\
France & 1.90 & 641 & $\approx 99.0$ \\
India & 0.90 & 37 & 71.2 \\
Pakistan & 0.67 & 15 & 58.0 \\
& $0.90^{\mathrm{b}}$ & $20^{\mathrm{b}}$ & \\
Saudi Arabia & 0.25 & 60 & 94.7 \\
\hline
\end{tabular}

Note: $\mathrm{a}=$ the literacy rate is measured against a world average literacy rate of 86.1 percent; $\mathrm{b}=$ including military R\&D.

Source: UNESCO Institute of Statistics. 


\subsection{Pakistan's Dilemma}

Pakistan's low civilian R\&D expenditure (among the lowest in the world) means that it cannot hope to catch up with the West any time soon; if this level of investment in science continues, it may even be left behind most Asian countries. The country also faces other constraints. Its low literacy rate - on average, 58 percent, with 70 percent among males and only 46 percent among females in 2015 - means that Pakistan has a very small pool from which to draw its intelligentsia, including scientists. The country's education system, both at the K-12 level and beyond, suffers from inadequate, outdated science curricula. Its research infrastructure, where it exists, is in a shambles (with some exceptions). There is also a perceived dearth of technicians and other professionals able to support sustainable scientific research. The biggest problem, of course, is the lack of political will to invest in science - this includes science and mathematics education, technical training and advanced research.

While the NSTIP addresses many of Pakistan's science needs, it almost completely ignores GCC, which could have ominous consequences for the country's food, health and economy. While the broader consequences of GCC are being debated by the world's scientific community, what is already clear is that these effects will vary considerably from region to region. Of course, for the same reason, solutions to GCC effects will have to be regional and local, not global. We cannot just import solutions from another region and apply them locally. We will have to find our own solutions. Ignoring this will catch us unawares and unprepared with calamitous results for society and the economy. Indigenous research and inventory is urgently needed to chart local GCC effects because the associated economic and social setbacks will be severe.

The fact that the Himalayan glaciers that feed our rivers are retreating too rapidly is an example of just how urgent the situation is. As global mean atmospheric temperatures increase due to GCC, glaciers at high latitudes and high altitudes are retreating worldwide. They have already retreated by about 30 percent, on average, during the last century and are now retreating even more rapidly. Particularly in decline are the 15,000 odd glaciers of the Himalayas, which are retreating at $30 \mathrm{~m} /$ year, on average. These include the glaciers that feed all the rivers in India and Pakistan. At the current rate of retreat, predictions for the Subcontinent and the approaching water shortage are indeed critical. 


\subsection{Global Climate Change Predictions for Pakistan}

That the climate is changing rapidly around the world is no longer a surprise to anyone. GCC is already underway and the debate on whether it is being caused by anthropogenic activity or is due primarily to natural factors is almost extraneous at this point. One detail that the climate research has established in recent years is that the way in which GCC affects different latitudes and regions will vary widely, depending on the geography and topography of the area. There will not be a uniform rise in the mean temperature everywhere, as is often conveyed by the commonly used label of "global warming" for these changes. The current preferred epithet used by climate scientists is "global climate weirding."

In the case of Pakistan, some likely scenarios under this climate weirding have already been foreseen, evident from ongoing events. First and foremost, water resources will become very thinly stretched all over the Subcontinent due to the permanent loss of the Himalayan glaciers. As mentioned above, mountain glaciers are retreating rapidly all over the world due to the temperature increase at higher altitudes; the Himalayan glaciers are no exception. This translates directly into the looming severe water shortage. An additional effect of this temperature rise at higher altitudes is that, during the winter monsoon months, much of the rain is not converted to snow. Instead, the water rushes down the rivers in the shape of severe floods - as recent years have amply demonstrated in Pakistan. This means that the climate in Pakistan will alternate between serious droughts and major floods with all their attendant detrimental consequences for society and the economy. Another prediction for the region is the spread of desertification further north into Punjab's prime food-growing areas. As is already evident, tropical diseases such as malaria, dengue fever and the Zika virus will spread to higher latitudes. Other infectious viral mutations that are unknown at present are also likely to increase (e.g., avian flu). Many of these effects are already underway.

Any socioeconomic plans we make for the country without taking into account the looming impact of GCC and necessary mitigation steps will be meaningless. When these events unfold, Pakistan's resources may be too thinly stretched; any immediate unplanned effort to counter a new event (not envisioned in our long-term economic plans) may not be possible. To prepare for all contingencies will require indigenous research by climate scientists in Pakistan working in close collaboration with economists, social scientists and policymakers. Climate science in the broader sense - not just metrology, but also modeling to hindcast as well as 
forecast GCC effects in the region - is an area in which Pakistan needs to train more graduates and first-rate researchers. Currently, this capability is nonexistent.

\subsection{Potential Solutions}

What are the solutions to Pakistan's dilemma, given the many constraints it faces? Earlier, I mentioned that we should try to emulate China, but it is not easy to follow a model that has a centrally managed political system: any articulation by Beijing or provincial leaders is almost immediately translated into public policy, while state agencies act on this equally rapidly and at the peril of their organizational health. We can learn a great deal from China nonetheless. Some of the steps Pakistan's policymakers could take - that have proven to produce positive results include the following:

- Improve school and college science curricula, which are exceedingly outdated.

- Train school and college instructors in modern mathematics and science concepts.

- Train substantially more technicians in all fields of scientific research at polytechnic institutions; these service providers form the backbone of research labs and organizations.

- Introduce a significant (possibly tenfold) increase in governmentfunded PhDs abroad. For China, this policy has paid high dividends with relatively modest investment and been a key factor in enabling the country to catch up with the West in all major sciences in a fairly short time. China has flooded many Western universities with graduate students in the last three decades.

- China has also put in place considerable monetary inducements as well as facilities to attract expat Chinese scientists back home. Similar incentives could also be used in Pakistan to encourage some of the best minds in the world to return.

- Significantly increase science funding agency budgets (e.g., for the Pakistan Science Foundation and others) to a minimum of 1.5 percent of GDP and eventually to 2 percent of GDP.

- Longer-term plans should include an emphasis on target sciences that are considered socioeconomically important for the country. 
- The US NSF model of hubs or nodes could be employed as academiaindustry partnerships and as added incentives for innovation.

\section{Conclusion}

This short discussion of the importance of indigenous research for sustainable development concludes that, if Pakistan does not develop local capabilities in scientific research, especially in subjects considered relevant to its growth, it cannot achieve the kind of sustainable development to which it aspires.

While the NSTIP is a fairly comprehensive plan, it has not been fully promulgated and has already failed to meet its 2015 target of allocating 1 percent of GDP to expenditure on science and technology research. The policy also ignores the consequences of GCC, leaving Pakistan unprepared for the dire results that this may have. Indigenous research is urgently needed in this context. The rate at which the Himalayan glaciers, which feed Pakistan's rivers, are retreating illustrates this urgency, given the looming severe water shortage for the country. 